\title{
Vantagens e limites da metodologia de facilitação de conflitos socioambientais: o caso de Canabrava (MG)
}

\author{
Luís Tadeu Assad \\ Doutor em Desenvolvimento Sustentável (Universidade de Brasília)
} Instituto Ambiental Brasil Sustentável

Elimar Pinheiro do Nascimento Doutor em Sociologia (Université René Descartes - Paris V) Professor na Universidade de Brasília

Gabriela Litre

Doutora em Desenvolvimento Sustentável (Universidade de Brasília) Doutora em Geografia, Ordenamiento Territorial y Urbanismo (Universite Paris III/Sorbonne Nouvelle) Pesquisadora na Universidade de Brasília

Resumo Os conflitos socioambientais, se não manejados da forma adequada e no momento certo, podem gerar custos sociais e ambientais irreversíveis. Este trabalho analisa as vantagens e os limites da aplicação da metodologia de facilitação, utilizando-se de um estudo de caso: o conflito envolvendo uma comunidade de produtores rurais e uma empresa florestal multinacional no norte de Minas Gerais. Alguns objetivos da facilitação foram alcançados, sobretudo a mudança da percepção do conflito pelos atores, o reconhecimento entre eles e uma maior disponibilidade ao diálogo. Contudo, a relação entre os atores não evoluiu o suficiente para a composição de um espaço de diálogo. Três fatores demonstraram-se relevantes na facilitação: a temporalidade, os recursos disponíveis e a resistência por parte dos atores. Concluímos que é possível construir uma relação de acordos positivos, desde que haja uma instituição facilitadora de confiança entre os atores, um ambiente de predisposição ao diálogo e disponibilidade de tempo.

Palavras-chave: conflitos socioambientais; gestão de conflitos.

\section{Introdução}

$\mathrm{D}$ ESDE O FINAL DO SÉCUlO XX, transformações sociais velozes afetam significativamente as relações da sociedade com o meio ambiente (Salmon, 2002) e, por diversas razões, geram conflitos. Alguns desses tipos de conflitos, com relevância nas últimas décadas, são os socioambientais, envolvendo interpretações distintas e contraditórias no plano internacional. Embora não seja objeto deste artigo, deve-se referir, para compreender o debate internacional, aos artigos de Hagmann (2005) e Libiszewski (1992). Se não existe consenso na literatura para conceituar conflito, mais difícil é o terreno dos conflitos socioambientais.

De acordo com Simmel (1995), apesar de o senso comum da sociedade moderna apontar o conflito como algo indesejável, este é parte constituinte do comportamento humano. Se ele aporta mazelas e prejuízos, às vezes de monta, desempenha, normalmente, um papel essencial na construção da norma e da coesão social. É por meio do conflito que 
os homens definem as suas regras de conviviabilidade, modificam o status de seus membros, definem o campo dos interesses. Assim, ele deve ser visto como um fator de evolução, de transformação das relações sociais e definição de regras, normas e leis (Nascimento, 2001).

Os conflitos socioambientais relacionados com disputas de natureza social, econômica e ambiental são objeto de diversas definições. Little (2001) define-os como "disputas entre grupos sociais derivadas dos distintos tipos de relação que eles mantêm com seu meio natural". Esse conceito envolve a dimensão natural e a humana, assim como o relacionamento entre ambas. A Fundação Futuro Latino-Americano (FFLA) define o conflito socioambiental como "um processo de interação coletiva caracterizado por uma dinâmica de oposição e controvérsia entre grupos de interesses, resultante de suas incompatibilidades, reais ou percebidas, em torno do controle, uso e/ou acesso ao ambiente e seus recursos" (Dumas; Luna, 2008). Acserald (2004), por sua vez, enfatiza que o uso dos recursos naturais é sujeito a conflitos entre distintos projetos, sentidos e fins durante o processo de reprodução social. Dessa forma, afirma que a questão ambiental é intrinsecamente conflitiva, embora nem sempre seja reconhecida como tal.

Essas conceituações avaliam o conflito socioambiental como um tipo que se diferencia dos demais por envolver disputas em torno das relações com os recursos naturais e seus usos, cuja titularidade de direitos, por vezes, é de difícil identificação. Isso empresta a esse tipo de conflito uma característica que ficou evidenciada na disputa pelo uso de carvão vegetal entre uma empresa multinacional e uma comunidade de agricultores familiares em Canabrava, município de Guaraciama, no norte de Minas Gerais, que ganha visibilidade com o assassinato de um agricultor em fevereiro de 2007, objeto deste artigo.

Esse fato - e sua grande visibilidade na mídia especializada - ensejou a experiência de intervenção do Instituto Ambiental Brasil Sustentável (IABS), com uso da metodologia de facilitação, que permite a criação de espaços de diálogo para dar uma resposta rápida a conflitos socioambientais com risco de escalada de violência. A experiência foi escolhida e financiada por meio da primeira convocatória regional do Fundo Resposta, iniciativa da Fundação Futuro Latino-Americano (FFLA), com recursos do Banco Interamericano de Desenvolvimento (BID) e da Corporação Andina de Fomento (CAF), que procuram fornecer respostas rápidas a conflitos socioambientais potencialmente violentos por meio de intervenções de tempo limitado (Dumas; Luna, 2008).

Em virtude do tempo contratual - quatro meses -, a metodologia não foi aplicada em sua plenitude, restringindo-se a três das suas quatro etapas, descritas e analisadas neste texto. As duas primeiras visitas de campo por parte da equipe do IABS procurou avaliar a situação por meio de observações, entrevistas informais, reconhecimento de localidades e atores envolvidos para definir as estratégias de trabalho. Nessa etapa, foram mapeados os principais atores e iniciado o processo de mobilização para as quatro oficinas por grupos de atores. A terceira visita de campo, com a presença de dois membros da FFLA como observadores, iniciou a intervenção.

A análise dessa intervenção possibilitou a formulação da questão deste artigo: a gestão de conflitos socioambientais, por intermédio da metodologia de facilitação, está apta a criar condições para a construção de um espaço de diálogo?

\section{Metodologia aplicada}

O objeto da intervenção do IABS foi o conflito entre a comunidade rural de Canabrava, localizada no município de Guaraciama, na microbacia do rio Canabrava, e a proprietária da fazenda Pé de Morro, uma empresa florestal dedicada à produção de eucalipto e carvão vegetal para a indústria siderúrgica. Essa fazenda ficou conhecida por ter sido o cenário, em fevereiro de 2007, do assassinato do agricultor Antonio Joaquim dos Santos, aparentemente por um segurança de uma empresa terceirizada. ${ }^{1}$

Optou-se, entre as metodologias de gestão de conflitos socioambientais, pela de facilitação (Carpenter; Kennedy, 1983). Segundo Bush e Folger (2005), a facilitação é o processo informal no qual uma terceira parte, neutra, sem poder de impor uma decisão, ajuda as partes em disputa a buscarem um acordo mutuamente aceitável. Na nossa definição, facilitação é um processo no qual uma terceira parte busca construir com os atores direta ou indiretamente envolvidos caminhos de interação pacífica em espaços legitimados de diálogo, como forma de se buscar acordos para questões conflituosas. O objetivo é criar uma práxis de discussão de dissensos e propostas de desenvolvimento em um ambiente construtivo e colaborativo.

O processo de facilitação na gestão de conflitos socioambientais tem hoje duas correntes básicas, a de resolução (the problem-solving approach) e a de transformação (the transformative approach) do conflito (COHN, 2002). A primeira está comprometida com a obtenção de resultado para o conflito, com claras limitações: a estreiteza do escopo, o rígido foco em resultados quantificáveis e a tentativa de eliminar o risco. Já a segunda, a de transformação, aqui adotada, enfatiza a capacidade de intervir para iniciar e ensejar crescimento social. As partes são ajudadas a se 'empoderar' e criar mecanismos para definir as questões e decidir acordos por meio de um entendimento das perspectivas de cada parte.

No Quadro 1, são apresentadas algumas diferenças entre resolução e transformação de conflitos socioambientais: 
Quadro 1 - Diferenças principais entre os enfoques de resolução e transformação de conflitos socioambientais

\begin{tabular}{|l|l|l|}
\hline & RESOLUÇÃO DE CONFLITOS & TRANSFORMAÇÃO DE CONFLITOS \\
\hline $\begin{array}{l}\text { Pergunta } \\
\text { central }\end{array}$ & Como damos fim a algo não desejado? & $\begin{array}{l}\text { Como damos fim a algo destrutivo e construímos algo } \\
\text { positivo? }\end{array}$ \\
\hline Propósito & $\begin{array}{l}\text { Conseguir um acordo e uma solução ao problema que } \\
\text { gera a crise, mesmo que de caráter temporário }\end{array}$ & $\begin{array}{l}\text { Promover mecanismos de interação que proporcionem } \\
\text { processos de mudança legítimos e construtivos }\end{array}$ \\
\hline $\begin{array}{l}\text { Desenvolvimento } \\
\text { processo }\end{array}$ & $\begin{array}{l}\text { Preocupa-se pelas imediações da relação de onde apa- } \\
\text { rece o problema -'remediar' }\end{array}$ & $\begin{array}{l}\text { Preocupa-se por responder aos sintomas e identificar } \\
\text { as suas raízes - 'prevenir e remediar' }\end{array}$ \\
\hline $\begin{array}{l}\text { Visão temporal } \\
\text { Visão do conflito }\end{array}$ & $\begin{array}{l}\text { Horizonte de curto prazo (imediato), porém cíclico } \\
\text { processos do conflito }\end{array}$ & $\begin{array}{l}\text { Horizonte de médio e longo prazos (passado, presente } \\
\text { e futuro), porém efetivo }\end{array}$ \\
\hline $\begin{array}{l}\text { Atenção ao tema de } \\
\text { poder }\end{array}$ & $\begin{array}{l}\text { Ausente } \\
\text { Visualiza a dinâmica de fluxo (redução da escalada do } \\
\text { conflito) } \\
\text { e refluxo (manifestação do conflito para obter a mu- } \\
\text { dança construtiva) }\end{array}$ \\
\hline
\end{tabular}

Fonte: Baseado em Bush e Folger (2005) e Cohn (2002).

Partiu-se da premissa de que o conflito é um processo natural e inerente a todas as sociedades, pois é o resultado dos valores, percepções e dos interesses divergentes entre os atores, a que se deve acrescentar, segundo Dietz, Stern e Rycroft (1989), no caso dos conflitos socioambientais, a desconfiança do conhecimento perito.

Nessa perspectiva, o objetivo da facilitação é transformar o conflito socioambiental em oportunidade para melhorar as condições de desenvolvimento sustentável de uma região. O conflito pode desencadear uma crise com enfrentamentos e custos sociais e ambientais elevados ou até mesmo irreversíveis, mas, se for manejado a tempo e de forma adequada, pode atuar como agente transformador.

Assim, a metodologia de facilitação, em sua vertente de transformação aqui adotada, busca identificar as reais causas do conflito e facilitar a criação de espaços de diálogo entre os atores para a sua gestão pacífica, associando a dimensão objetiva e subjetiva. ${ }^{2}$

O conjunto de técnicas adotadas na intervenção, embora embasado na literatura geral sobre a metodologia de facilitação (Busterud, 1981, Sandole et al., 2009), alimentou-se, em seu enriquecimento, do texto da FFLA (Dumas; Luna, 2008) e, sobretudo, dos trabalhos de Assad (2002), Fishtec (2003), Correa e Rodriguez (2005), Assad, et al. (2006, 2007), e IABS (2007).

Com o fim de garantir um mínimo de representatividade dos grupos de atores, durante as entrevistas semiestruturadas, utilizou-se a técnica de ciclo de indicações, na qual a todos se perguntou quais são as pessoas mais representativas e envolvidas no desenvolvimento local. As pessoas mencionadas foram entrevistadas, indicando novas pessoas. Dessa maneira, foi construído o mapa de atores de cada grupo.

Durante a intervenção, adotou-se o princípio da flexibilidade metodológica. Assim, criaram-se atividades distintas das originalmente previstas para responder às demandas que surgiram, ao passo que outras foram suprimidas ou consideradas não aptas. A seguir, citam-se as quatro etapas da metodologia adotada, com suas respectivas atividades.

Etapa 1 - Avaliação técnico-participativa do processo de desenvolvimento local e do conflito socioambiental: elaboração do diagnóstico de construção do território do conflito e sua dinâmica socioambiental; identificação dos vetores de origem do conflito, sua caracterização, seu campo de ação e

2 De um modo geral, o processo de facilitação de um conflito se diferencia da mediação por não intervir diretamente no processo de diálogo entre atores. Enquanto o facilitador analisa o conflito e suas relações sociais e dirige o processo de criação de um espaço de diálogo, o mediador coordena o diálogo entre os atores. 
atores participantes, com suas inter-relações. Para tal, foram utilizados levantamentos de dados e informações secundárias, disponíveis em sites, publicações e órgãos públicos, consultas, vivência do processo, levantamento de informações técnicas e entrevistas direcionadas em profundidade com personalidades locais de influência histórica e/ou com visão do contexto de desenvolvimento local.

Etapa 2 - Atores e suas proposições: identificação das percepções, dos interesses e valores dos atores, por meio de entrevistas semiestruturadas e oficinas por grupo de atores. Elaboração de um quadro de questões sobre a origem do conflito, baseado em informações coletadas entre os atores. Finalmente, os próprios moradores, por meio da construção da 'linha de tempo', identificaram os fatos (positivos e negativos) da vida da comunidade. Não se buscou uma cronologia exata, apenas uma contextualização dos fatos percebidos ao longo do tempo.

Dessa forma, foram definidos quatro grupos de atores, quais sejam: setor privado, organizações e comunidades locais, poder público e terceiro setor/universidades.

Etapa 3 - Pré-negociação: avaliação da legitimidade e representatividade dos atores e do espaço de diálogo (passos, condições e elementos centrais); empoderamento e equalização de atores e construção de estratégias (análise e integração de proposições por grupo de atores, proposição de metas e etapas do processo de gestão). Embora de forma inconclusa, por razões que serão explicitadas, propostas de soluções socioambientais para o conflito foram relatadas durante as entrevistas e oficinas participativas.

As informações por grupos de atores foram devidamente registradas, validadas e, após autorização, apresentadas aos demais grupos de atores envolvidos.

Etapa 4 - Criação e implementação do espaço de diálogo: construção de regras de convivência entre atores; implementação de espaço(s) de diálogo ou fórum(ns) de interação(ões) consensuados; conexão com sistemas formais de decisão.

Com os espaços de diálogo definidos e ativos, os próprios atores, com ou sem intervenção, buscam acordos e sua consequente formalização e implementação.

No caso em análise, não foi possível alcançar essa etapa, por razões que serão explicitadas ao longo do texto.

\section{Guaraciama e Canabrava}

A Comunidade de Canabrava, com cerca de 350 habitantes, e a fazenda Pé de Morro, estão localizadas na zona rural do município de Guaraciama, região de Montes Claros, ao norte de Minas Gerais. A cidade de
Guaraciama dista $399 \mathrm{~km}$ de Belo Horizonte, ao passo que a Comunidade de Canabrava dista aproximadamente $12 \mathrm{~km}$ da sede do município.

A população registrada do município de Guaraciama era de 4.708 habitantes em 2008 (IBGE, 2008). A sede municipal apresenta aproximadamente 53\% dos habitantes. A densidade demográfica é de 12,4 hab. $/ \mathrm{km}^{2}$. A população é relativamente jovem, pois a maioria encontra-se na faixa etária entre 0 e 19 anos. O IDH é de 0,689, abaixo da média do estado com 0,766, e do país, de 0,792 (PNUD, 2000). A região do norte de Minas é conhecida por ser a maior produtora de carvão vegetal, proveniente de áreas de eucalipto e do Cerrado.

Segundo Brito (2006), a política florestal em Minas Gerais teve em sua trajetória dois momentos singulares, quais sejam: a) o desmatamento das matas nativas para a expansão da fronteira agropecuária e para o abastecimento da construção civil e das indústrias siderúrgicas; e a política de criação de incentivos fiscais do governo federal, entre 1960 e 1980, incrementando o plantio. Essa política do Estado teve como objetivo estimular a modernização regional. As condições topográficas favoráveis e o baixo preço das terras foram decisivos para a implantação dessas plantações de eucalipto no norte mineiro (Associação Mineira de Silvicultura, 2004).

A linha do tempo: a comunidade de Canabrava e a empresa florestal

A dinâmica do conflito foi construída com os moradores de Canabrava por meio da técnica de linha do tempo, expressa no Quadro 2. Observe-se que estes, até o momento da intervenção, não possuíam acesso aos meios de comunicação nem a espaços públicos para se exprimirem.

\section{Origens e vetores do conflito socioambiental}

Talvez o ponto mais crítico, evidenciado na oficina com moradores, e que acirrou as insatisfações da comunidade com a empresa, ocorreu em razão do desemprego e da falta de alternativas de renda, associados à degradação do meio ambiente. Para reduzir custos e garantir maior lucratividade, a empresa automatizou o trabalho. "Uma máquina substitui cerca de 70 motosserristas", segundo depoimentos dos moradores. A introdução de novos fornos também dispensou muitos trabalhadores. Segundo Carrere (2003), a terceirização das atividades de extração de madeira e produção de carvão foi adotada como política de redução de custos. Em 2001, dos 2.142 que trabalhavam para a empresa, 672 eram empregados diretos e 1.470 eram terceirizados. 
Quadro 2 - Cronologia de fatos positivos e negativos ocorridos em Canabrava, de acordo com a oficina realizada com moradores (ago. 2007)

\begin{tabular}{|c|c|}
\hline Avaliação & Fato percebido \\
\hline हो) & $\begin{array}{l}\text { "A vida era boa. A gente pegava pequi, mangaba, peixe. As mulheres faziam doce com os frutos do Cerrado. Pegávamos } \\
\text { lenha sem problema. As coisas não tinham dono. Tudo era de todos". }\end{array}$ \\
\hline 直 & "Foi construída a Igreja N.Sa da Conceição Aparecida". \\
\hline$\Leftrightarrow$ & "Chegou a carvoeira, a empresa, que se instalou primeiro na Fazenda Extrema. No começo era bom, pois deu emprego". \\
\hline s & $\begin{array}{l}\text { "Com a chegada da empresa, começou a perda da cultura local, os nomes locais mudaram. Começou a secagem das } \\
\text { nascentes". }\end{array}$ \\
\hline$\Leftrightarrow$ & "Foi construído um posto de saúde em Guaraciama. Começou a construção das estradas". \\
\hline$\Leftrightarrow$ & "Nasceu a escola da comunidade". \\
\hline 得 & $\begin{array}{l}\text { "Começa a chegar gente de fora, os 'carvoeiros', que pegam lenha para fazer carvão e vender. A empresa começou a } \\
\text { mandar a polícia". } \\
\text { "Começou o êxodo rural por falta de emprego". }\end{array}$ \\
\hline s & "... A empresa começou a mandar gente embora. Trouxe máquinas para cortar a lenha". \\
\hline$\Leftrightarrow$ & "Teve a emancipação de Guaraciama". \\
\hline s & $\begin{array}{l}\text { "Nesse ano foi construído um poço artesiano. Começou a água encanada, antes água era de graça, agora temos que } \\
\text { pagar até } 10 \text { reais". }\end{array}$ \\
\hline (s) & "Foi feita a nucleação das escolas". \\
\hline s & "Chegou a luz, foi muito bom". \\
\hline 急 & $\begin{array}{l}\text { "Chegou a outra empresa que se associou à antiga. A situação ficou péssima: mecanizou ainda mais, ficamos sem Cerrado } \\
\text { e sem trabalho". "Teve crimes na propriedade da empresa, foram assassinadas várias pessoas". }\end{array}$ \\
\hline 里 & $\begin{array}{l}\text { "A empresa contratou guardas armados. A empresa antes não tinha isso. A situação piorou com a perseguição aos mo- } \\
\text { radores". }\end{array}$ \\
\hline (1) & "Chegou a Cooperativa Grande Sertão, que está fazendo projetos de agricultura alternativa". \\
\hline s & $\begin{array}{l}\text { "A relação com a empresa piorou, ficou muito ruim". "Em fevereiro, o Antonio foi morto na frente da filha. O resto da } \\
\text { família estava por perto". }\end{array}$ \\
\hline$\Leftrightarrow$ & "Após a morte do Antonio, a comunidade ficou mais mobilizada, mais unida e mais informada sobre nossos direitos". \\
\hline
\end{tabular}

Legenda: Negativo; Positivo

Fonte: Assad et al. (2007).

Adicionalmente, os impactos do monocultivo de eucalipto na região geraram a escassez de recursos naturais, comprometendo a sobrevivência da comunidade. Um retrato desse sentimento encontra-se no relatório de certificação florestal da Empresa. Durante as audiências públicas realizadas em Curvelo e Montes Claros (24-29 set. 2003), quatro consequências da monocultura foram ressaltadas pela população e respondidas pela empresa, conforme o Quadro 3.

Durante as entrevistas e as quatro oficinas realizadas por grupos de atores (agosto de 2007) em Guaraciama, foram identificadas outras razões do conflito, conforme a Figura 1. 
Quadro 3 - Impactos do monocultivo de eucalipto suscitados nas audiências públicas de certificação da Empresa Florestal

\begin{tabular}{|l|l|l|}
\hline $\begin{array}{l}\text { Questões levantadas pelas comunidades } \\
\text { em geral }\end{array}$ & Argumentos da Empresa Florestal \\
\hline A monocultura do eucalipto seca o solo. & $\begin{array}{l}\text { "Outros tipos de uso da terra também chegaram ao Cerrado junto com o eucalipto, principal- } \\
\text { mente a agricultura irrigada na bacia do rio Riachão". "Estão sendo conduzidos projetos com } \\
\text { UNILESTE e UFLA para a recuperação da mata ciliar e aumento da captura de água". }\end{array}$ \\
\hline $\begin{array}{l}\text { O eucalipto não é adaptado para o Cer- } \\
\text { rado: se a área de plantio for reduzida os } \\
\text { mananciais de água retornam. }\end{array}$ & $\begin{array}{l}\text { "A Empresa retirou os cultivos da cabeceira do rio Canabrava, limpou a área e vai mantê-la sem } \\
\text { plantios para que a nascente possa se recuperar". }\end{array}$ \\
\hline $\begin{array}{l}\text { Plantios de eucalipto expulsam a fauna sil- } \\
\text { vestre. }\end{array}$ & $\begin{array}{l}\text { "A Empresa vem conduzindo com a UFMG estudos de monitoramento de pássaros, mamíferos } \\
\text { cies habitando a região, como } 23 \text { espécies de médios e grandes mamíferos, dos quais nove são } \\
\text { espécies ameaçadas de extinção; } 293 \text { espécies de pássaros foram registradas, sendo } 6 \text { ameaça- } \\
\text { das. Isso demonstra que espécies da fauna nativa estão buscando abrigo nas áreas da Empresa". }\end{array}$ \\
\hline $\begin{array}{l}\text { A poluição com pesticidas e iscas para for- } \\
\text { migas utilizadas pela Empresa têm causado } \\
\text { mortandade de peixes. }\end{array}$ & $\begin{array}{l}\text { "Aão sejam autorizados no estado de Minas Gerais". "A Empresa reconhece o uso de aplicações } \\
\text { aéreas de pesticidas e fertilizantes, mas não é rotina". }\end{array}$ \\
\hline
\end{tabular}

Figura 1: Síntese das questões levantadas pelos atores envolvidos no conflito socioambiental na região de Canabrava. Fonte: Adaptado de Fanzeres (2005).

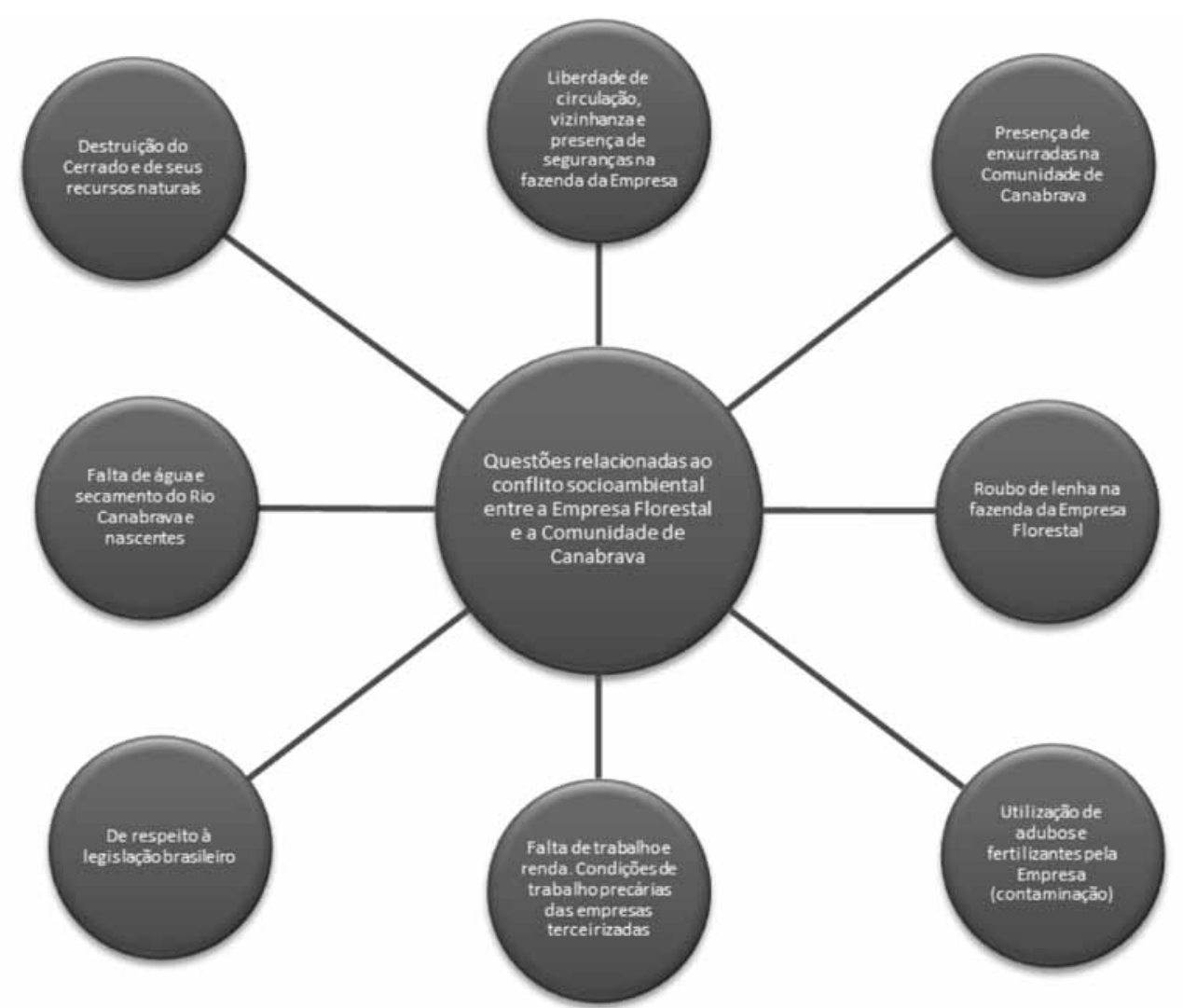

Fonte: Assad et al. (2007). 
O caso de Canabrava demonstra, na prática, até que ponto a disputa pelo uso de recursos naturais (neste caso, carvão vegetal e recursos hídricos) pode se transformar em enfrentamento, com consequências ambientais e sociais irreversíveis, pois as tensões comprometem as relações sociais entre os atores, gerando o deterioramento irreparável de recursos naturais e a perda do sustento da vida de populações inteiras.

\section{Principais grupos de atores envolvidos no conflito}

Os atores foram agrupados e seus posicionamentos, relacionamentos e interações, destacados. Vale ressaltar que esse agrupamento é um artifício metodológico para iniciar uma discussão com atores, cujas funções sociais, posturas ou interesses são semelhantes em relação ao desenvolvimento da região. Observou-se, no entanto, uma grande variedade de posturas e interesses em um mesmo grupo de atores.

$\mathrm{Na}$ descrição a seguir, esses grupos são caracterizados em relação ao conflito socioambiental. Algumas interpretações iniciais e atitudes em relação ao processo de gestão de conflitos evoluíram durante a intervenção.

\section{Grupo I - O Setor Privado}

O grupo do setor privado é composto por empresas e organizações dos empresários envolvidos no desenvolvimento local e/ou na produção silvícola da região norte de Minas Gerais: Federação das Indústrias de Minas Gerais (FIEMIG), Associação Mineira de Silvicultura (AMS), Federação das Associações Comerciais, Industriais de Minas Gerais (FEDERAMINAS), a Empresa Florestal envolvida no conflito, e sua fundação, uma prestadora de serviços (comunicação) para a Empresa Florestal e outras empresas florestais com menor atuação na área.

O foco principal desse grupo é a Empresa Florestal, que atua em 18 municípios de Minas Gerais, com 26 fazendas entre 1.000 e 36.000 hectares, totalizando cerca de 240 mil hectares, dos quais 140 mil ocupados com plantações de eucalipto. Compreende também 1.219 fragmentos de vegetação nativa englobando uma área de 72.865 hectares. Atua igualmente na exploração do eucalipto em propriedades de terceiros (Carrere, 2003).

A Empresa tinha a certificação ambiental ISO 14.001, pelo sistema do FSC em 1999 e recertificada em 2004. Entretanto, em 2007, solicitou o desligamento da certificação ao Conselho de Manejo Florestal, segundo o site da Empresa, depois da morte de Joaquim.

Durante a gestão do conflito, a Empresa Florestal foi desde o início a principal opositora à gestão do conflito, esgrimindo quatro razões a seguir: as relações en- tre a Empresa e os moradores de Canabrava eram boas e não existiam tensões; a morte do agricultor tinha sido efetuada por um segurança da Empresa em "defesa própria"; a palavra "conflito" era negativa e conotava grau de tensão inexistente na comunidade; e as reclamações quanto a Empresa e a morte do agricultor "limitavam-se a um grupo de criminosos sem representatividade na comunidade e envolvidos num grande esquema de roubo organizado de madeira e carvão vegetal". Tais reclamações foram contrariamente comprovadas pelas entrevistas e oficinas com moradores e atores do poder público e do terceiro setor/ universidades.

Apesar disso, a Empresa participou ativamente de todas as atividades da intervenção, inclusive solicitando reunião na sede do IABS, em Brasília, para conhecimento da metodologia.

As demais empresas expressaram interesse em alcançar um acordo com os moradores e aceitar as regras de convivência propostas. Agiam do mesmo modo alguns funcionários da Empresa que, em reserva, expressavam apoio ao processo e admitiam que o conflito existia, e que era grave.

Oficialmente, a Empresa permaneceu afirmando ao longo da intervenção que não reconhecia a existência do conflito.

\section{Grupo II - A Comunidade de Canabrava}

A Comunidade de Canabrava, perto de uma centena de famílias entrelaçadas ao longo das gerações, encontra-se cercada por plantios de eucalipto de diversas empresas. Segundo o que expressou a presidenta do Sindicato de Trabalhadores Rurais, a comunidade vive de lavoura de milho, feijão, mandioca, biscoito caseiro e derivados de mandioca, que entregam à $\mathrm{CO}$ NAB. A comunidade enfrenta um grave problema de escassez de água, particularmente no período da seca, além de problemas de desemprego e pouca renda.

São três associações locais, divididas com base na bacia hidrográfica, Cabeceira, Médio e Barrinha, que foram criadas para buscar projetos comunitários locais, como a implantação de energia, auxílio do Programa Bolsa Escola e do Fome Zero, segundo um dos técnicos do Centro de Agricultura Alternativa.

A Comunidade é vista pelas localidades vizinhas como possuidora de um alto grau de coesão social e forte sentido de identidade. Rica em lideranças, ela possui ao menos dois tipos de representantes. De um lado, lideranças que participam do Sindicato de Trabalhadores Rurais e das organizações não-governamentais (Centro de Agricultura Alternativa, Rede Alerta Contra o Deserto Verde, Pastoral da Terra, MST e Via Campesina). Tal participação, que estimula vínculos e articulação discursiva, permite que seus membros assumam o papel de liderança. De outro, lideranças vinculadas à Cooperativa Grande Sertão, cuja missão é organizar a produção de 
produtos agroecológicos artesanais, fazer o beneficiamento e encaminhar o produto ao mercado, com respeito ao meio ambiente, compromisso social e valorização dos ecossistemas (Gonçalves; Santa Rosa, 2005).

Também existem as 'novas lideranças', mulheres e jovens que têm começado a questionar as condições de vida de suas famílias e a falta de opções de educação, cultura, lazer e atividades laborais para os jovens.

A Comunidade de Canabrava se mostrou receptiva à equipe de facilitação. Inclui-se nesse rol a família do agricultor assassinado, que participou das reuniões. Em geral, os agricultores mantiveram uma posição moderada e otimista com respeito à Empresa e ao conflito.

\section{Grupo III - Poder Público}

Os órgãos públicos foram menos atuantes no conflito, apesar de suas funções institucionais. Estiveram presentes nas entrevistas e oficina as prefeituras de Guaraciama e Bocaiúva, a EMATER, a Delegacia da Polícia Civil de Bocaiúva, o Instituto Estadual de Florestas (IEF), o Ministério Público, a Comissão de Direitos Humanos da Assembleia Legislativa, a Secretaria da Agricultura do Estado, a Polícia Militar Ambiental e o Conselho de Política Ambiental.

Durante as entrevistas e a oficina, os participantes expressaram sua preocupação pela morte do agricultor e afirmaram que a Empresa não estava cooperando para atingir a solução do conflito, apesar de alguns manterem relações de parceria com a mesma.

\section{Grupo IV - Terceiro Setor e Universidades}

Apesar de estarem no mesmo grupo, as ONGs, universidades, cooperativas e a Igreja Católica manifestaram interesses e posições diferenciados em relação ao conflito.

Foram entrevistados e participaram da oficina do grupo as seguintes instituições: Universidade Federal

Figura 2 - Mapa das interações de alianças entre os grupos de atores envolvidos no conflito socioambiental da região de Canabrava

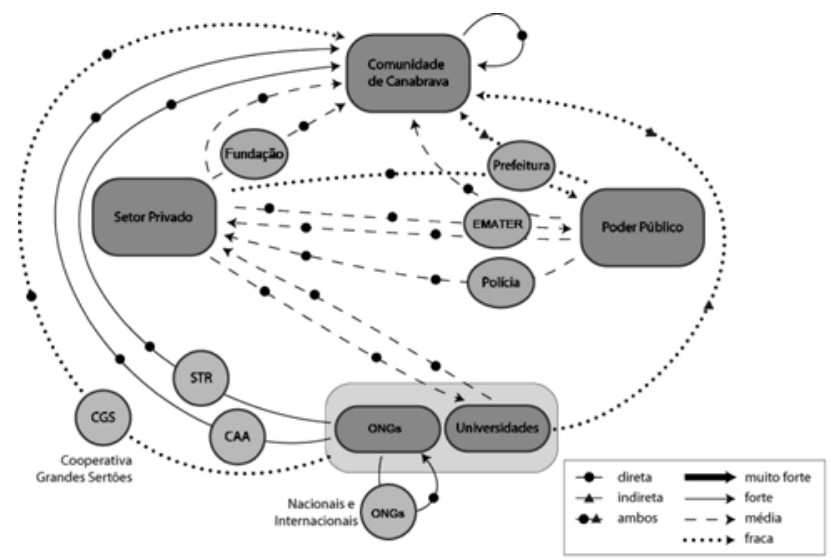

Fonte: dados elaborados pelos autores com base em Assad et al. (2007). de Minas Gerais (UFMG), Universidade de Montes Claros (UNIMONTES), Centro de Agricultura Alternativa (CAA), Cooperativa Grande Sertão, a Comissão Pastoral da Terra (CPT) de Montes Claros e a Rede Alerta Contra o Deserto Verde. Essa rede enviou à imprensa a notícia da morte do agricultor, alertando o terceiro setor nacional e internacional.

Os atores do Grupo IV tinham em comum o temor de que a intervenção do IABS funcionasse como um colchão para abrandar as tensões ou que fosse uma estratégia da Empresa.

Apesar disso, grande parte desses atores considerava a intervenção do IABS um momento único para forçar mudanças radicais na forma de operar da Empresa.

\section{Retrato das posturas dos grupos de atores}

O Quadro 4 resume as posições, os interesses, as estratégias e os recursos de cada grupo de atores. Essas caracterizações foram baseadas nas informações coletadas e na posição assumida durante a oficina de grupo.

Considerando as informações dos grupos de atores, foi construído o mapa de interações, com representações gráficas da classificação das alianças e dos conflitos. Ressalte-se que essa classificação varia para cada ator, segundo a interação social e os cenários de desenvolvimento.

A Figura 2 representa as relações de alianças por grupo de atores, onde o STR é o Sindicato dos Trabalhadores Rurais e o CAA, o Centro de Agricultura Alternativa.

Entre as relações de aliança, merece destaque o apoio do terceiro setor e das universidades à comunidade de Canabrava, buscando fortalecê-la.

Por sua vez, a Figura 3 representa as relações conflituosas entre os grupos de atores envolvidos, onde o FSC é o Conselho de Manejo Florestal, filial no Brasil. Essas relações foram classificadas e representa-

Figura 3 - Mapa das interações de conflito entre os grupos de atores envolvidos no conflito socioambiental da região de Canabrava

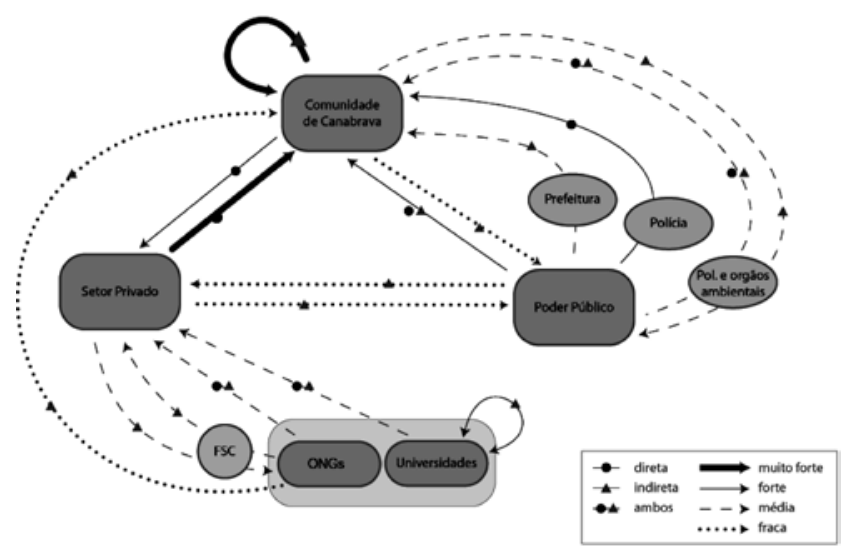

Fonte: dados elaborados pelos autores com base em Assad et al. (2007). 
Quadro 4 - Posições, interesses, estratégias e recursos dos grupos de atores envolvidos no conflito socioambiental da região de Canabrava

\begin{tabular}{|c|c|c|c|c|}
\hline $\begin{array}{c}\text { Grupo de } \\
\text { atores }\end{array}$ & Posição & Interesses & Estratégias & RECURSOS \\
\hline 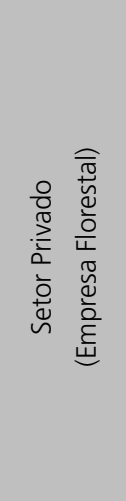 & $\begin{array}{l}\text { Manter seu sis- } \\
\text { tema produtivo, } \\
\text { seus rendimentos } \\
\text { e imagem }\end{array}$ & $\begin{array}{l}\text { - Acabar com o roubo de le- } \\
\text { nha na fazenda; } \\
\text { - manter a lucratividade e me- } \\
\text { Ihorar a imagem da Empresa; } \\
\text { - evitar que o conflito gere im- } \\
\text { pactos negativos para si; } \\
\text { - melhorar as questões socio- } \\
\text { ambientais locais; } \\
\text { - evitar enfrentamentos e con- } \\
\text { flitos com a comunidade. }\end{array}$ & $\begin{array}{l}\text { - Criar um diálogo com atores selecio- } \\
\text { nados; } \\
\text { - desenvolver projetos socioambientais } \\
\text { em parceria com a comunidade; } \\
\text { - empresa de comunicação para melho- } \\
\text { rar a sua imagem; } \\
\text { - incentivar o poder público a solucionar } \\
\text { os roubos de lenha; } \\
\text { - deslegitimar lideranças e instituições } \\
\text { contrárias; } \\
\text { - questionar a existência de conflito. }\end{array}$ & $\begin{array}{l}\text { - Poder econômico; } \\
\text { - influência política; } \\
\text { - geração de trabalho; } \\
\text { - conhecimentos técnicos } \\
\text { e de comunicação; } \\
\text { - relações com outras } \\
\text { empresas e outros ór- } \\
\text { gãos públicos; } \\
\text { - fundação de apoio à } \\
\text { comunidade. }\end{array}$ \\
\hline 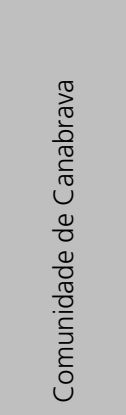 & $\begin{array}{l}\text { Melhoria de suas } \\
\text { condições de vida }\end{array}$ & $\begin{array}{l}\text { - Geração de trabalho e renda, } \\
\text { melhoria da qualidade de vida; } \\
\text { - investimento para desenvol- } \\
\text { vimento da comunidade; } \\
\text { - acesso à terra e aos recursos } \\
\text { naturais; } \\
\text { - liberdade de circulação; } \\
\text { - recuperação dos recursos na- } \\
\text { turais (água e cerrado). }\end{array}$ & $\begin{array}{l}\text { - Buscar parcerias para fortalecer o po- } \\
\text { der de negociação com a Empresa; } \\
\text { - realizar manifestações populares; } \\
\text { - buscar alternativas de emprego e ren- } \\
\text { da; } \\
\text { - proteger os recursos naturais da região; } \\
\text { - fortalecer o associativismo e buscar } \\
\text { parcerias para a execução de projetos } \\
\text { socioambientais. }\end{array}$ & $\begin{array}{l}\text { - Manifestação popular; } \\
\text { - organização social; } \\
\text { - parcerias com ONGs de } \\
\text { repercussão regional, na- } \\
\text { cional e internacional; } \\
\text { - conhecimentos empí- } \\
\text { ricos e do histórico da } \\
\text { região. }\end{array}$ \\
\hline $\begin{array}{l}\frac{0}{0} \\
\frac{.0}{2} \\
\frac{1}{2} \\
\frac{\bar{d}}{0} \\
0\end{array}$ & $\begin{array}{l}\text { Neutro e omisso, } \\
\text { alguns a favor da } \\
\text { Empresa e outros } \\
\text { a favor da comu- } \\
\text { nidade. }\end{array}$ & $\begin{array}{l}\text { - Melhorar a qualidade de vida } \\
\text { dos habitantes de Guaraciama } \\
\text { e das comunidades rurais da } \\
\text { região; } \\
\text { - fazer cumprir as leis e os di- } \\
\text { reitos e deveres do cidadão; } \\
\text { - desenvolvimento econômico } \\
\text { da região. }\end{array}$ & $\begin{array}{l}\text { - Fiscalizar o cumprimento de leis, com } \\
\text { a integração de ações e conscientização; } \\
\text { - resolver os processos judiciais de roubo } \\
\text { de lenha; } \\
\text { - contribuir com projetos socioambien- } \\
\text { tais na comunidade, ações de assistência } \\
\text { social e técnica rural. }\end{array}$ & $\begin{array}{l}\text { - Investimentos limita- } \\
\text { dos; } \\
\text { - inserção local a partir } \\
\text { de ATER; } \\
\text { - poder de polícia e fisca- } \\
\text { lização; } \\
\text { - poder político limitado; } \\
\text { - Conhecimentos legisla- } \\
\text { tivo, jurídico e executivo. }\end{array}$ \\
\hline 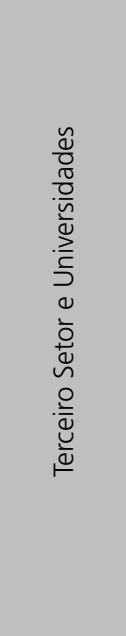 & $\begin{array}{l}\text { Terceiro Setor: a } \\
\text { favor da comuni- } \\
\text { dade e contra a } \\
\text { monocultura do } \\
\text { eucalipto. } \\
\text { Universidades: } \\
\text { algumas a favor } \\
\text { da comunidade e } \\
\text { outras a favor da } \\
\text { Empresa. }\end{array}$ & $\begin{array}{l}\text { - Redução da monocultura do } \\
\text { eucalipto; } \\
\text { - Melhoria da qualidade de } \\
\text { vida das comunidades locais; } \\
\text { - Reforma agrária e garantia } \\
\text { de acesso à terra para as co- } \\
\text { munidades; } \\
\text { - Proteção do Cerrado e dos } \\
\text { recursos hídricos; } \\
\text { - Recursos para projetos e pes- } \\
\text { quisas; } \\
\text { - Pesquisas científicas sobre } \\
\text { os impactos dos plantios de } \\
\text { eucalipto. }\end{array}$ & $\begin{array}{l}\text { - Divulgar o conflito, a morte do agri- } \\
\text { cultor e os problemas socioambientais } \\
\text { como forma de mobilizar a sociedade e } \\
\text { pressionar a Empresa; } \\
\text { Empoderar a comunidade sobre seus } \\
\text { direitos; } \\
\text { - Fornecer orientações jurídicas e técni- } \\
\text { cas para a comunidade; } \\
\text { - Contribuir com projetos socioambien- } \\
\text { tais; } \\
\text { - Realizar pesquisas científicas sobre os } \\
\text { impactos dos plantios de eucalipto e sua } \\
\text { redução. }\end{array}$ & $\begin{array}{l}\text { - Divulgação em mídia; } \\
\text { - Rede, parcerias com } \\
\text { universidades, movimen- } \\
\text { tos sociais e ONGs; } \\
\text { - Mobilização; } \\
\text { - Conhecimento técnico; } \\
\text { - Conhecimentos cientí- } \\
\text { ficos; } \\
\text { - Espaços de debate so- } \\
\text { bre o desenvolvimento } \\
\text { local sustentável. }\end{array}$ \\
\hline
\end{tabular}


das como "muito forte", "forte", "média" e "fraca", e são exercidas de forma direta, indireta ou ambas, de acordo com a legenda de cada figura.

Dentre as relações conflituosas, merecem destaque) a da Empresa para com a comunidade mediante a contratação de seguranças armados, a diminuição na geração de emprego, a homogeneização e degradação do meio ambiente) entre membros da própria comunidade com pessoas que se beneficiam com o roubo de lenha, o que gera relação de desconfiança por parte da Empresa) a da comunidade com o poder público, pela parcialidade da polícia, abuso de autoridade, multas elevadas e falta de fiscalização da Empresa) e, finalmente, entre as universidades com visões dicotômicas, principalmente em relação à introdução das plantações de eucalipto.

\section{Identificação de necessidades e construção de proposta}

Algumas propostas de soluções socioambientais para o conflito entre a Comunidade de Canabrava e a Empresa Florestal foram relatadas durante as entrevistas e as quatro oficinas participativas realizadas com os grupos de atores, totalizando 84 pessoas.

Apesar do contexto ambiental visível do conflito, grande parte dos atores ressaltava a geração de emprego como forma de solucionar o conflito como um todo. Outros mencionaram a recuperação das áreas degradadas, a transformação de plantações de eucalipto em vegetação nativa e a cessão de terras da Empresa para a comunidade. E outros citavam o cooperativismo, áreas de lazer, novas alternativas de renda e melhoria da educação e da saúde

\section{Resultado}

Ao longo da intervenção, que durou quatro meses, todos os grupos modificaram, em maior ou menor medida, as suas percepções sobre o conflito e as suas atitudes, independentemente de suas estratégias e percepções iniciais. As informações geradas e divulgadas - com autorização de todos - contribuíram para essas transformações. Foram divulgadas as agendas de atividades e resultados de reuniões e oficinas.

A opção de difundir amplamente os objetivos e atividades do projeto, com a maior objetividade e transparência possíveis, tem contribuído para alimentar a confiança dos atores envolvidos e sua disposição ao dialogo. (observadores do processo/FFLA)
Por isso, deve-se ressaltar o papel da estratégia de comunicação na gestão de conflitos, dando publicidade às ações e atividades agendadas e executads, e criando uma confiança no processo. A publicização, por sua vez, cria condições de pressão sobre os atores para cumprirem os acordos e se portarem de forma que corresponda às expectativas dos outros atores, e à própria imagem que eles vão criando no processo de trabalho. ${ }^{3}$

$\mathrm{Na}$ construção de relações de confiança, a desconfiança inicial transformou-se em cooperação ativa, no caso da Comunidade e do setor público; moderada, no caso do terceiro setor; e atentiva, no caso do setor empresarial. Apesar da aderência à proposta metodológica e da criação de vínculos de confiança na instituição facilitadora (IABS), a relação entre os atores não teve tempo suficiente de evoluir para a composição de um espaço de diálogo. $\mathrm{Na}$ verdade, este já estava se esboçando na medida em que os atores se dispunham a se reunir e auscultar uns aos outros.
A comunidade está aberta ao diálogo, temos vontade de melhorar as coisas... estamos dispostos a trabalhar juntos com a Empresa. (oficina com Moradores)
É possível realizar um diálogo entre todos... (oficina com Poder Público)
A Empresa está sempre disposta ao diálogo, prova dis- to é estar aqui falando com transparência... (oficina Setor Privado)
Acreditamos que seja possível sentar-se à mesa de diá- logo com a Empresa, se a Empresa tiver propostas para solucionar o conflito. (oficina com Terceiro Setor/ Universidades)

A criação de um espaço de diálogo esteve seriamente condicionada por dois lados. O primeiro, o lado do IABS e do Fundo Resposta, pelas limitações de tempo (quatro meses). Pelo lado dos atores, pela atitude da Empresa, que resistiu e tentou desqualificar o processo de gestão do conflito, atrasando-o.

A Empresa demorou a integrar-se no processo de negociação, pois negava legitimidade aos representantes comunitários, a quem acusava de participar de uma rede organizada de roubo de madeira e carvão. Também questionava a legitimidade do facilitador, já que este havia descrito a morte do agricultor como "assassinato" (o que depois foi modificado) e tinha difundido a notícia da intervenção usando a palavra "conflito".

A desconfiança da Empresa em relação a um processo baseado em percepções foi discutida, demonstrando-se que "todo sujeito vive e age segundo as suas percepções do mundo e das situações que o rodeiam, 
pois a subjetividade é uma característica essencial do ser humano" e que o term "conflio" pode ter conotações positivas, segundo os componentes do IABS.

Em relação ao prazo de intervenção, foi possível constatar que o tempo necessário é aquele exigido pelos tempos emocionais das partes na criação de laços de confiança.

O exíguo tempo dificultou uma resposta consistente às expectativas geradas na comunidade rural, no terceiro setor e no poder público. De toda forma, o IABS, antes de se retirar do campo, realizou ações de devolução de resultados e publicou suas análises. ${ }^{4}$

Dessa forma, a limitação temporal não impediu a percepção da mudança dos atores, porém não permitiu auferir até que ponto elas evoluiriam na construção de projetos comuns de desenvolvimento local. Faltaram etapas essenciais do processo, como a construção participativa de regras e procedimentos do espaço de diálogo, a formalização dos acordos e o seu monitoramento.

Do ponto de vista metodológico, a facilitação não procura reduzir ou polarizar o conflito e sim valorizar a pluralidade de visões. As atividades executadas corresponderam em grande parte à estratégia original, marcada, desde o começo, pela flexibilidade. Em se tratando de relações humanas, muitos outcomes são imprevisíveis, especialmente em situação de conflito com muitos atores. Atividades foram criadas ao longo do processo para responder às demandas, como por exemplo, a construção da "linha de tempo".

Em virtude do apoio incondicional de alguns atorese particularmente dos moradores, parte dos objetivos da facilitação foram alcançados. Dentre estese destaca-se o reconhecimento entre os atores e a aproximação das partedebaseada em uma caracterização adequada "desnuda" do conflito.

Dentre os fatores que facilitaram a intervenção, destacam-se os seguintes:a) - a organização comunitária existente (em parte pela ação de ONGs e da EMATER);b) - paradoxalmente, a morte do agricultor permitiu uma percepção da gravidade do conflito.

Por outro lado, alguns obstáculos ocorreram, com destaque para) o pouco tempo e os limites de recursos financeiros para a intervenção) a grande distância física entre os atores) as dificuldades iniciais de construir laços de confiança fortes no processo e na legitimidade do facilitadore particularmente com a Empresa) a falta de planos e projetos futuros organizados coletivamente entre os agricultores;e) a necessidade de melhorar ferramentas e estratégias de comunicação para a difusão equilibrada da intervenção, sem danificar o procedimento de facilitação.

\section{Conclusões}

A facilitação tenta substituir as relações de desconfiança por ações colaborativas por meio do diálogo. Esse objetivo é dificultado quando partes do conflito entram no processo sem interesse de conciliação.

Comprovou-se que a facilitação tem dificuldades específicas em situações com uma grande assimetria do poder ou quando aconteceram danos irreparáveis a um ou mais dos grupos. $\mathrm{O}$ assassinato do agricultor desempenhou o duplo papel de dramatizar o conflito, propiciando a intervenção do IABS e dos poderes públicos, e criou um clima desfavorável ao diálogo.

Algumas das lições apreendidas na experimentação podem assim ser resumidas.

Este tipo de intervenção pode ser pertinente e gerar boas condições para a gestão de conflito, sobretudo para evitar novas escaladas de violência. $\mathrm{Na}$ experiência concreta, as oficinas realizadas mostraram que a dramaticidade da situação foi sendo ultrapassada e os atores começaram a se escutar.

Parece possível reduzir a assimetria de poder entre os atores, graças à valorização da comunicação e do diálogo, considerando-os como de mesmo peso e legitimidade para expor suas expectativas. As oficinas mostraram que os moradores se articularam e formularam propostas.

As tentativas de confrontação, adotadas por alguns atores, tendem a ganhar menos espaço na medida em que os demais tendam a se afastar das posições extremas, escutando os argumentos apresentados. Tais argumentos devem se basear em interesses e necessidades reais, afastando-se de posições estanques. Vale ressaltar que alguns atores tendem a jogar o papel d "destensionador" " do conflito.

A metodologia não é uma receita, mas um roteiro de intervenção, devendo ser recriada em cada experimento, suprimindo atividades, introduzindo outras, e sem linearidade.

Aparentemente, em uma situação onde todos têm medo de "perde" e não se pode antever resultados, é possível construir uma relação de acordos a partir da constituição de espaços de diálogo efetivos. As condições de sucesso metodológico, portanto, residem na existência desse ambiente propício de interação e na capacidade da intervenção ganhar a confiança dos atores, com transparência e honestidade.

Finalizando, não achamos que todo e qualquer conflito socioambiental deva sofrer esse tipo de intervenção, ou que seja possível transformá-lo em um espaço de diálogo a qualquer custo. Nem a experiência permite essa ilação. No entanto, se os atores demonstram a mínima vontade do diálogo e a natureza da disputa não é de ordem antagônica, pode ser uma metodologia em que todos ganham, embora uns mais que outros. 


\section{Referências}

ACSERALD, Henri. (Org.). Conflitos ambientais no Brasil. Rio de Janeiro: Relume Dumará, Fundação Heinrich Böll, 2004.

ASSAD, Luís Tadeu et al. Tradição - modernidade - sustentabilidade. Icapuí,CE: Os desafios do desenvolvimento de uma comunidade diante do imperativo da sustentabilidade. Brasília, Tese (Doutorado em Desenvolvimento Sustentável) - Centro de Desenvolvimento Sustentável, Universidade de Brasília, 2002.

ASSAD, Luís Tadeu et al. Projeto Diálogos: resultados de atividades econômicas de larga escala selecionadas nas microrregiões do projeto. Brasília: Centro de Desenvolvimento Sustentável (CDS)/Universidade de Brasília (UnB), 2006.

ASSAD, Luís Tadeu et al. A vida por um feixe de lenha: o conflito entre a empresa florestal e os agricultores familiares do norte de Minas Gerais - Caracterização do conflito e descrição do processo de facilitação do espaço de diálogo. Brasília, relatório apresentado à FFLA como resultado do processo de intervenção do Fundo Resposta, 2007.

ASSOCIAÇÃO MINEIRA DE SILVICULTURA. O Complexo Florestal Industrial (CFI) em Minas Gerais. Caracterização, Dimensionamento e Importância. 2004. Disponível em: <http://www. silviminas.com.br>. Acesso em: 10 ago. 2007.

BRITO, Isabel Cristina Barbosa. Comunidade, território e complexo industrial florestal: o caso de Vereda Funda, Norte de Minas Gerais. Montes Claros, MG. Dissertação (Mestrado em Desenvolvimento Social)-. Unimontes, 2006

BUSH, Robert A e FOLGER, Joseph P. The promise of mediation: the transformative approach. 2. ed. rev. San Francisco: Jossey-Bass Publishers, 2005.

BUSTERUD, John. Environmental conflict resolution. Environmental Science \& Technology, v. 15, n. 2, p. 150155, 1981.

CARPENTER, Susan L e KENNEDY, W. J. Managing public disputes: a practical guide to handling conflict and reaching agreements. Hardcover, Wiley \& Sons. Incorporated, 1983.

CARRERE, Ricardo. Certificando o não-certificável. Certificação pelo FSC de plantações de árvores na Tailândia e no Brasil. Movimento Mundial pelas Florestas Tropicai, Ddez. 2003.

COHN, Jeffrey P. Environmental conflict resolution. BioScience, v. 52, n. 5, p. 400-404, 2002.

CORREA, Hernán Dário; RODRÍGUEZ, Iokiñe (Eds.). Encrucijadas Ambientales en América Latina. Entre el manejo y la transformación de conflictos por recursos naturales. Costa Rica: Universidad para la Paz, 2005.

DIETZ, Thomas; STERN, Paul C.; RYCROFT, Robert
W. Definitions of conflict and the legitimation of resources: the case of environmental risk. Sociological Forum, v. 4, n. 1, p. 47-70, 1989.

DUMAS, Juan; LUNA, Diego. Fondo Respuesta para a América del Su: una experiencia para la construcción de mecanismos de respuestas temprana a conflictos socioambientales en América Latina. Quito: FFLA, 2008. FANZERES, Anna. Temas conflituosos relacionados à expansão da Base Florestal Plantada e definição de estratégias para minimização dos conflitos identificados. Programa $\mathrm{Na}-$ cional de Florestas, Secretaria de Biodiversidade e Florestas, Ministério do Meio Ambiente. Projeto MMA/ FAO/TCP/BRA/2902. Relatório Final de Consultori,. 2005.

FISHTEC. Caracterização e avaliação da sustentabilidade socioambiental do processo de desenvolvimento da carcinicultura marinha em Icapuí , CE. Brasília: FISHTEC, 2003.

GONÇALVES, Breno; SANTA ROSA, Helen. Cooperativa Grande Sertão: articulando populações e diversidades do Norte de Minas Gerais. Revista Agriculturas, v. ,, n. 2, p.17-21, 2005.

HAGMANN, Tobias. Confronting the Concept of Environmentally Induced Conflict. Peace, Conflict and Development, uix6, ja., 2005.

IABS: Instituto Ambiental Brasil Sustentável. Plano Diretor Participativo de Itarema/CE. Brasília: Iabs, 2007.

IBGE: Inatituto Brasileiro de Geografia e Estatística. Estimativas da população para $1^{\circ}$ de julho de 2008. Disponível em: <http://www.ibge.gov.br/home/estatistica/ populacao/estimativa2008/POP_2008_TCU.pdf> (29 ago. 2008). Acesso em: 10 abr. 2009.

LIBISZEWSKI, Stephan. What is an environmental conflict? Environmental and Conflicts Projet/ ENCOP Occasional Papers. Zurich: Swiss Peace Foundation, 1992. LITTLE, Paul E. Os conflitos socioambientais: um campo de estudo e de ação política. In BURSZTYN, Marcel (Org.). A difícil sustentabilidade: política energética e conflitos ambientais. Rio de Janeiro: Garamond, 2001 NASCIMENTO, Elimar Pinheiro do. Os conflitos na sociedade moderna: uma introdução conceitual. In: BURSZTYN, M. (Org.). A difícil sustentabilidade: política energética e conflitos ambientais. Rio de Janeiro: Garamond, 2001.

PNUD. Ranking decrescente do IDH-M dos municípios do Brasil. Atlas de Desenvolvimento Humano para o Brasil. 2000. Disponível em: <www.penud.org.br/atlas>. Acesso em: 10 abr. 2009.

SALMON, Jean Marc. Um mundo a grande velocidade. Lisboa: Ambar, 2002.

SANDOLE, Dennis. J. et al. (Orgs.). Handbook of conflict analysis and resolution. London: Routledge, 2009.

SIMMEL, Georg. Le conflit. Paris: Circé/poche, 1995. 


\title{
Advantages and limitations of the facilitation methodology in socioenvironmental conflicts: the case of Canabrava, MG
}

\begin{abstract}
If not managed in a proper and timely manner, socio-environmental conflicts may generate irreversible costs. This paper analyzes the advantages and limitations of the methodology of socio-environmental conflict facilitation through a case study: the clashes between a peasant community and a multinational forest company operating in Northern Minas Gerais, Brazil. In spite of the initial vote of trust obtained by the facilitators and of the overall acceptation of their methodology, the relationship among actors did not evolve rapidly enough to guarantee the implementation of an effective arena for dialogue. Three factors seem to have challenged the facilitation process: temporality, the available resources and the reluctance to cooperate by some of the involved actors. The experience shows that it is possible to build positive agreements in socio-environmental conflicts, once there is a trustworthy facilitator, a window to dialogue among the involved parts, as well as enough time..
\end{abstract}

Keywords: Socioenvironmental conflicts; conflict management.

\section{Ventajas y límites de la metodología de facilitación de conflictos socioambientales: el caso de Canabrava, MG}

\begin{abstract}
Resumen
Si no se manejan correctamente y en el momento adecuado, los conflictos socio-ambientales pueden generar costos irreversibles. Este trabajo examina las ventajas y limitaciones de la metodología de facilitación, por medio de un estudio de caso: el conflicto entre una comunidad de productores rurales y una empresa forestal multinacional en el Norte de Minas Gerais. Algunos de los objetivos de la facilitación se alcanzaron, como el cambio de la percepción de los actores sobre el conflicto, su mutuo reconocimiento y una mayor apertura al diálogo. Sin embargo, la relación entre los actores no ha evolucionado lo suficiente como para construir un espacio adecuado de diálogo. Tres factores parecen influir en la facilitación: la temporalidad, los recursos existentes y la resistencia de los actores. Llegamos a la conclusión de que es posible construir acuerdos positivos, desde que haya confianza de los actores en la institución facilitadora y que haya un ambiente de predisposición al diálogo y tiempo disponible.
\end{abstract}

Palabras Clave: conflictos socio-ambientales; gestión de conflictos

Data de recebimento do artigo: 13-07-2010

Data de aprovação do artigo: 12-01-2011 